\title{
Current and future Industry 4.0 capabilities for information and knowledge sharing
}

\section{Case of two Swedish SMEs}

\author{
Dan $\mathrm{Li}^{1}$ (D) $\cdot$ Åsa Fast-Berglund ${ }^{1} \cdot$ Dan Paulin $^{2}$
}

Received: 30 July 2018 / Accepted: 24 May 2019 / Published online: 20 June 2019

(C) The Author(s) 2019

\begin{abstract}
Humans are indispensable in the manufacturing industry as its complexity increases in an Industry 4.0 context, mainly due to changing customer demands. Managing the challenges of increased complexity can create a competitive advantage for SMEs. Technologies which enable the emerging phenomenon of Industry 4.0 have the possibility to simplify the sharing of information and knowledge among people at work, especially for Operator 4.0. However, few SMEs have actually implemented such technologies for this purpose. Therefore, this paper aims to create an understanding of the current state and challenges which need to be overcome, and further, to provide some insights on future possibilities by identifying the stages of Industry 4.0 development of SMEs with regards to their capabilities. This qualitative interview study focuses on how human-centered production processes are currently supporting assembly and office work. Two Swedish SMEs were studied, where almost all of their operators and management team on site were interviewed individually concerning their views on their current capabilities. The interviews were thematically analyzed with regards to the state-of-the-art research, and results show that the case companies are in some aspects digitized with regards to computerization and connectivity, but have some challenges in making the shared production-related information more visible and transparent, especially on shop-floors where most information and knowledge are shared through word of mouth or with pen and paper. Conclusively, the studied SMEs have started their digitalization journey, but further Industry 4.0 development needs to align with their respective conditions and needs. While Industry 4.0 enabling technologies that support information and knowledge sharing are emerging, organizational development can support the implementation of such technologies, which should be the focus for future research.
\end{abstract}

Keywords Information sharing $\cdot$ Knowledge sharing $\cdot$ Industry $4.0 \cdot$ Operator $4.0 \cdot \mathrm{SME}$

\section{Introduction}

The manufacturing industry is becoming increasingly more complex with regards to a higher product variety in assembly systems [1]. This development from mass production towards a closer catering of individual customers' needs put new demands on modern production systems [2]. Instead of solely mitigating

Dan Li

dan.li@chalmers.se

1 Department of Industrial and Materials Science, Chalmers University of Technology, 41296 Gothenburg, Sweden

2 Department of Technology Management and Economics, Chalmers University of Technology, 41296 Gothenburg, Sweden the challenges of complexity, a competitive advantage can be gained by embracing the complexity that can improve the performance of assembly systems [1]. The demands for individualized products are shifting high volume mass production towards a batch-size-of-one production [3]. This has led to an increase in complexity, which calls for the implementation of technologies that can support such transition [4]. This technology-driven development of the manufacturing industry, Industry 4.0 [4], creates a new level of interaction between actors and resources involved in modern production systems [5]. The promises of Industry 4.0 are going to be realized by skilled operators on shop-floors that are cyber-physical systems [6]. The presence of the human operators on shop-floors, which in essence are socio-technical systems [2], is vital for managing complexity [1], interaction and initiatives [5], coordination and problem-solving [6], and decision-making [7]. 
This skilled operator of the future, introduced by Romero et al. [8] as Operator 4.0, can and should be aided in various ways to create socially sustainable workplaces, for example with smart wearables [9]. Then, the dissemination of information and knowledge becomes important to cognitively aid humans at work $[8,10]$. To manage the aforementioned increase in production complexity, more information and knowledge need to be shared among operators and managers [11], especially for large manufacturing companies with high product variety [12]. Recent technological development has benefitted such knowledge management practices [13] and demonstrators have been created as proofs-of-concept [14]. Even though large companies are moving in this direction, it remains difficult for SMEs to implement digital technologies related to Industry 4.0 for such purposes, albeit more and more SMEs are becoming more and more ready for it $[15,16]$, in Sweden [11], in France [17], as well as in Germany [18, 19].

The purposes of this paper are to provide some insights into how SMEs consider their current digitalization status and give a future outlook concerning information and knowledge sharing in a human-focused Industry 4.0 context. The current capabilities of the studied SMEs are explored in terms of their Industry 4.0 maturity [20] in four structural areas and are further discussion explore how the development of Industry 4.0 capabilities can support Operator 4.0 [8] in Assembly System 4.0 [10].

\section{Industry 4.0}

Industry 4.0 as a genre is well-researched [21]. In this paper, Industry 4.0 is regarded as a technology-driven [4] paradigm shift [2] of the manufacturing industry [22] that will digitally integrate production networks both horizontally and vertically [5]. This development will benefit humans working in Industry 4.0 context ergonomically, both physical [23, 24] and cognitive [25]. However, concerning cognitive ergonomics, focusing on the information and knowledge needs of humans working in Industry 4.0 SMEs are published to a lesser extent.

In this paper, Industry 4.0 Maturity Index [20] is used to assess the current production-related information and knowledge sharing capabilities at studied SMEs. With regards to the current capabilities, the development towards future capabilities is discussed by applying the characteristics of Assembly System 4.0 [10].

\subsection{Related research}

Filtering in the Scopus database with titles, abstracts, or keywords containing information or knowledge, and further limitation to the keywords Industry 4.0 or Industrie 4.0, rendered 957 documents for the years 2014-2018. Within this set of documents, 55 papers contained SME. The abstracts of these papers were assessed with regards to whether its content indicated it to encompass either, some, or all of these three categories [26, 27]:

- Human: tendencies towards anthropocentrism, where human operators are considered on an individual level, including mention of decision-making, collaboration, or ICT tools, since it implies communication between people $[8,25]$.

- Technology: focus on Industry 4.0 enabling technologies, including ICT tools or IoT platforms.

- Organization: including management issues, business cases, value creation, and financial profitability.

The focus of this paper centers around humans sharing information and knowledge in SMEs within an Industry 4.0 context. Hence, this filtering of previous related research in this area. Out of the 55 documents, four documents did not focus on the manufacturing industry, six documents do not use $S M E$ as an abbreviation for small- and medium-sized enterprises, and 12 documents used the words information and knowledge in a sense that it regarded the general body of knowledge, through research or learning factories, that the document itself contributes to, and not information and knowledge that exists within SME. These documents were filtered out, leaving nine remaining documents within range, as listed in Table 1.

Considering this paper's human-centered focus of Industry 4.0, the nine documents that are listed in Table 1 after the screening shows that little previous research has been conducted concerning human aspects of information and knowledge sharing in SMEs and Industry 4.0. However, Industry 4.0 is very technology-driven, which is also reflected in Table 1 , where all the papers that consider human factors also deal with its interaction with automation, with the exception of one paper [31], which focused more on the humans in an organizational context. Five of the papers also connect human factors and technology to an organizational context [32-36].

Even though nine of the papers consider SMEs, only six papers [29-31, 33, 35, 36] have a clear targeting towards SMEs. None of the papers is actually stating that companies have actually achieved any level of Industry 4.0 implementation when it comes to information and knowledge sharing among people working in SMEs. Two papers propose software architecture [28, 29], three papers explore future opportunities [30-32], two papers have developed prototype tools that could be implemented $[33,35]$, and two papers review current state in relation to Industry $4.0[34,36]$. While Zhong et al. [34] reviews intelligent manufacturing in general, independent of SMEs or large companies, Neirotti et al. [36] focus on ICT-based capabilities with a quantitative research 
Table 1 Papers focusing on human aspects of information and knowledge in Industry 4.0 with SMEs in consideration

\begin{tabular}{|c|c|c|c|c|}
\hline Authors & Year & Ref. & $\begin{array}{l}\text { Additional focus, in addition } \\
\text { to human aspects }\end{array}$ & Summary of paper contents \\
\hline Ferrer and Lastra & 2017 & {$[26]$} & Technology & $\begin{array}{l}\text { Proposes an architecture for private local automation cloud, } \\
\text { that can store information and knowledge that end-users } \\
\text { on shop-floors can access. }\end{array}$ \\
\hline Dassisti et al. & 2018 & {$[27]$} & Technology & $\begin{array}{l}\text { Proposes a meta-model for formalized knowledge, exemplified } \\
\text { by applications concerning traceability, AR assembly support, } \\
\text { and data interpretation. }\end{array}$ \\
\hline Taylor et al. & 2018 & {$[28]$} & Technology & $\begin{array}{l}\text { Foresees an Operator as a Maker in an agile manufacturing context, } \\
\text { comparing SME manufacturers to designers. }\end{array}$ \\
\hline Quattrociocchi et al. & 2018 & {$[29]$} & Organization & $\begin{array}{l}\text { Emphasizes the importance of technical, methodological, social, } \\
\text { and personal competencies of SME employees. }\end{array}$ \\
\hline Barreto et al. & 2017 & {$[30]$} & Technology and Organization & $\begin{array}{l}\text { Introduces an overview of implications for logistics, } \\
\text { both in-house and transportation. }\end{array}$ \\
\hline Müller et al. & 2017 & {$[31]$} & Technology and Organization & Evaluates an ICT tool for vertical and cross-functional information sharing. \\
\hline Zhong et al. & 2017 & {$[32]$} & Technology and Organization & Reviews intelligent manufacturing in general. \\
\hline Gasparetto et al. & 2018 & {$[33]$} & Technology and Organization & $\begin{array}{l}\text { Proposes to implement a modular intelligent workpiece carrier with } \\
\text { an interface to support operators' with relevant information. }\end{array}$ \\
\hline Neirotti et al. & 2018 & [34] & Technology and Organization & Explores the use of ICT tools among SMEs. \\
\hline
\end{tabular}

approach. Hence, this paper's interest in exploring other capabilities with a qualitative research approach.

\subsection{Industry 4.0 Maturity Index}

For evaluating the level of readiness or maturity towards implementing aspects of Industry 4.0, various assessment tools exist [37, 38]. Brozzi et al. [37] review ten of such self-assessment tools for SMEs and conclude that there is no one-size-fits-all solution. Similarly, Wiesner et al. [38] review four maturity models with SMEs in consideration, with less emphasis on self-assessment as Brozzi et al. [37]. Wiesner et al. [38] conclude that the maturity models presented by Schumacher et al. [39], Jarrahi et al. [40], and Lichtblau et al. [41] are simpler to apply and require less knowledge about Industry 4.0 for the companies themselves compared to the maturity index presented by Schuh et al. [20]. However, However, the Industry 4.0 Maturity Index [20] was selected as a methodological foundation for this paper since it considers a more holistic approach including an emphasis on organizational issues, which is important when it comes to implementation of Industry 4.0 enabling technologies [11].

Schuh et al. [20] introduce four structural areas of businesses to study in order to assess the maturity towards Industry 4.0. These four structural areas are listed in Table 2 together with two guiding principles each, which explains which capabilities are necessary to attain Industry 4.0. These structural areas can then be applied to various functional areas of businesses. In this paper, the production is studied, with the delimitation towards human-centered shop-floor and related production management.

Resources include equipment, tools, materials, final products, and in this context also human resources [20]. The physical assets and humans contain and possess data, information, and knowledge tangible that are important to be shared and processed. The digital capability and structured communication entail two principles for resources' information-based working and its interaction with each other, respectively.

Information systems refer to a socio-technical system (i.e., shop-floors in this paper) and its ability to support decision-making with regards to the two principles of self-learning information processing and information system integration, which focus on the manner of preparation and usefulness of presented information as decision-making support and the integration of IT systems to enhance the presented information, respectively [20].

Organizational structure addresses formal positions and relations, both within a company internally and throughout the supply chain network external to the company [20]. Thus, the information and knowledge sharing within the principles of organic internal organization and dynamic collaboration within the value network.

Culture denotes softer organizational values and human behavior, focusing on a willingness to change and social collaboration [20], and further, how these two principles are supported by information and knowledge sharing. 
Table 2 The four structural areas and its guiding principles [20]

\begin{tabular}{ll}
\hline Structural area & Guiding principles \\
\hline Resources & Digital capability \\
& Structured communication \\
Information systems & Self-learning information processing \\
& Information system integration \\
Organizational structure & Organic internal organization \\
& Dynamic collaboration within the value network \\
Culture & Willingness to change \\
& Social collaboration \\
\hline
\end{tabular}

For each of these four structural areas, Schuh et al. [20] use a six-stage development path to assess the Industry 4.0 Maturity Index, where each stage needs to be attained before commencing the next stage. An adapted version of the six stages is presented in Fig. 1, where a stage 0 is introduced to represent the preceding pre-digitalization paradigm. Information and knowledge sharing in stage 0 are often characterized by oral "word of mouth" communication or written "pen and paper" communication.

The digitalization paradigm consists of computerization and connectivity, which provides a basis for future development. While both require the use of IT systems to support information and knowledge sharing, connectivity implies crude interoperability between IT systems while computerization let the IT systems remain in isolation to each other.

The Industry 4.0 paradigm is based on digitalization [42] but takes it further [20]. Visibility integrates IT systems to create a single source of truth, resolving contradictions. Transparency transforms this single source of truth to a digital shadow that supports aggregation of data and information. Predictive capacity uses the digital shadow and aggregation of data and information to better support human decisionmaking. Finally, adaptability allows certain decisions to be made autonomously. Along with the progress stage by stage, the IT landscape moves from basic digitalization through cross-functional connectivity enabling horizontal and vertical integration towards full digitalization with the adaptability of systems [42].

\subsection{Assembly System 4.0}

Industry 4.0 enabling technologies support the digitalization of the manufacturing industry. Bortolini et al. [10] list six characteristics of Assembly System 4.0, i.e., assembly work impacted by the implementation of Industry 4.0 enabling technologies:

- Aided assembly

- Intelligent storage management

- Self-configured workstation layout

- Product and process traceability

- Late customization

- Assembly control system

\section{Interviews with shop-floor operators and office workers}

There is a lack of SMEs having implemented Industry 4.0 enabling technologies with the purpose of improving information and knowledge sharing activities. For this particular study, two Swedish SMEs were selected based on their respective interest in improving internal communication, as expressed from their management teams. Shop-floor operators and office workers from these two SMEs were interviewed. Based on the interview results, the Industry 4.0 Maturity Index [20] was used to identify the two SME's current Industry 4.0
Fig. 1 Stages in the development path for Industry 4.0, i.e., maturity index, adapted from Schuh et al. [20] to also include stage 0

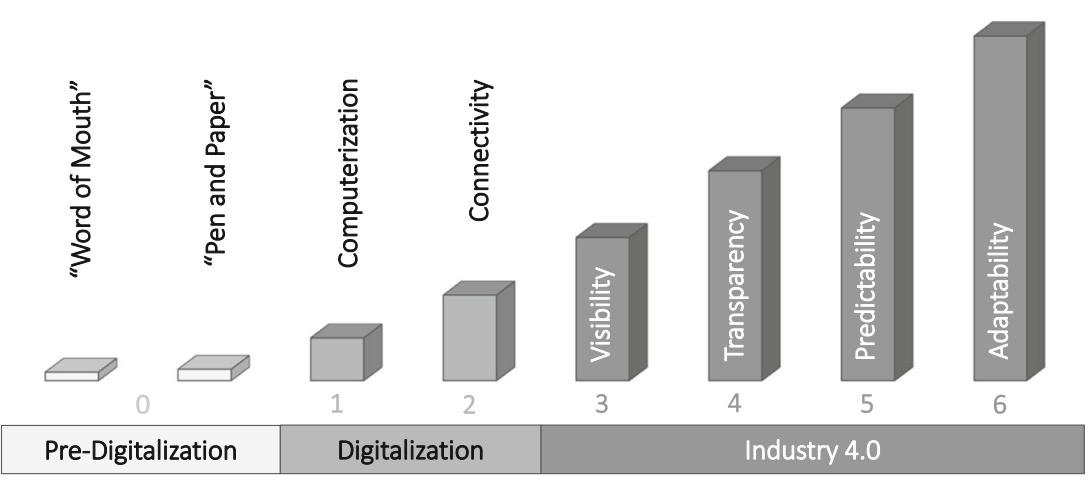


capabilities. The participation of the companies is listed in Table 3 .

Company A manufactures, sells, and installs heat and smoke exhaust ventilators and roof domes for the intake of natural light. At their main site, they have 11 employees including the CEO. Four employees work with sales and production management, and seven employees work on the shopfloor. All of their main site employees, except one operator, were interviewed. Additionally, several regional installation operators work from various other locations in Sweden.

Company B sells, installs, and provides service for scales and weighing information management systems. At their main site, they have five employees including the CEO, that work with sales and management. All of their main site employees were interviewed. Additionally, several regional installation and service operators work from various other locations in Sweden.

A semi-structured interview approach was selected to qualitatively understand the current capabilities of the selected SMEs. The interview questions were designed to be centered around production-related information and knowledge sharing with question areas aligned with the guiding principles of the four structural areas, as listed in Table 2, and with the aim of being able to make an assessment of the Industry 4.0 Maturity Index for each of the four structural areas, as listed in Fig. 1. The interviews were held individually, focusing on the interviewees' descriptions of current activities and thematically analyzed to allow for categorization within the structural areas to appear. With this thematic analysis, qualitative data is quantified for comparisons [43]. The trustworthiness of the results lies in the establishment of credibility, transferability, dependability, and confirmability of the research [44].

The interviews were conducted in Swedish, as it was the preferred language of the interviewees, an English translation of the questions of the interview guide is listed in Appendix.

\section{Results: Current Industry 4.0 capabilities}

The assessment of current Industry 4.0 capabilities is based on the interviews. The interview results for each group of interviewees, as listed in Table 3, were analyzed thematically together. Common themes among the interviewees are presented descriptively in Sects. 4.1, 4.2, and 4.3 with regards to the guiding principles from Table 2. Section 4.4 summarizes the capabilities across interview groups in terms of structural areas (Table 2) with maturity indices (Fig. 1) for each structural area and interview group.

\subsection{Shop-floor operators at company A}

The shop-floor operators at company A have different work tasks, ranging from machining to assembly. Six out of seven operators were interviewed as one operator declined participation.

\subsubsection{Resources}

Digital capability Within the planned work tasks, decisions made by operators themselves relate to the assembly work itself and which order to assemble components. These decisions are made based on the operators' own experiences or in discussions with the production manager. Necessary data for the assembly work consists predominantly of measurements of workpieces, which are acquired by using a folding rule/yardstick. The operators also do mental calculations with no digital support.

Structured communication Operators' communication with other operators on either the preceding or subsequent workstations is not standardized. To pass on information to the subsequent workstation, two operators use a pencil to write information on the work order sheet, two operators use felt pen to write information on the workpiece, and the remaining two operators go and talk to the next operator. These different practices may stem from different requirements for the various workstations that need to be addressed with different approaches.

\subsubsection{Information systems}

Self-learning information processing Aggregation of data and information that operators use on the shop-floor and that affect their decision-making are processed on a per work order basis. The operators need to interpret the data and information on the work order sheets themselves in order to make it useful for
Table 3 Participation sample of interviewees

\begin{tabular}{llll}
\hline Company & $\begin{array}{l}\text { Number of employees at their } \\
\text { main site }\end{array}$ & $\begin{array}{l}\text { Number of } \\
\text { interviewees }\end{array}$ & Group of interviewees \\
\hline A & 7 & 6 & $\begin{array}{l}\text { Shop-floor operators } \\
\text { Office workers, with operators in the } \\
\text { same building }\end{array}$ \\
B & 4 & 4 & $\begin{array}{l}\text { Office workers, with operators at other } \\
\text { locations }\end{array}$ \\
\hline
\end{tabular}


their assembly work context, which becomes easier with experience. These work order sheets, along with a daily control meeting constitute the major information sharing channels for the operators' work. However, there is little operator insight into how the data and information in the work order sheets are stored.

Information system integration The operators' information exchange with suppliers and customers outside the factory is very uncommon. An example of such rare information exchange can be feedback to suppliers about material and tool quality. However, this information is always passed along through the production manager.

\subsubsection{Organizational structure}

Organic internal organization Operators are assigned to specific workstations and are constrained to their associated work tasks. When issues or questions regarding certain products or specific work orders appear, the operators are often consulting with each other or the production manager. However, if a product-related decision needs to be made, the production manager is involved.

Dynamic collaboration within the value network Operators have no direct contact with end customers. Except for the product data and information on the work order sheets, the operators are not aware of the needs and wishes of the end customers.

\subsubsection{Culture}

Willingness to change Quality defects that occur are mostly detected in-house before shipping out to customers. When detected, individual operators' errors are discussed immediately with a problem-solving approach. Mistakes are also discussed during daily control meetings in terms of how the operator's work method can be improved based on the other operators' experiences in order to avoid future errors. For operators, learning new skills primarily constitutes of shadowing an operator that shows and tells about how to perform the work tasks of a specific workstation. The operators' opinions on how changes on the shop-floor are shaped and their possibility to affect these changes vary. Changes to product design and production planning are decided by the management team. Ideas related to simplification of work methods and shop-floor logistics are often initiated by the operators.

Social collaboration Some operators think that they can affect production-related changes if they want, but many choose not to. Half of the interviewed operators mention that they shared knowledge with colleagues on the shop-floor in order to improve either the work method for their colleagues specifically and for the company's performance in general. The operators trust the provided information in the work order sheet, except for this information, most of their work is based on own previous experiences.

\subsection{Office workers at company A}

The office workers at company A have different work tasks, including sales and management. Although having other work responsibilities than shop-floor operators, the office workers have direct, or indirect, information, and knowledge sharing with shop-floor operators, e.g., preparation of work orders. All four employees were interviewed concerning their information and knowledge sharing with the operators.

\subsubsection{Resources}

Digital capability Depending on which type of office work, the use of information and communication technology to support decision making varies. It can be e-mail correspondence for sales and the Enterprise Resource Planning system for computing the planning of production. Production data exists and is used for both sales and production planning but is gathered manually.

Structured communication Office workers' communication with each other is often done by talking to each other. Daily planning meetings are documented, but correspondence outside of these meetings is rarely documented.

\subsubsection{Information systems}

Self-learning information processing Most data and information regarding the products and work orders are stored in the ERP system, but processing is done manually and the office workers often need to make their own interpretations to contextualize the information for their own use.

Information system integration The office workers keep in contact with suppliers and customers. Most information exchange with customers is done by emails or phone calls. However, if customers call for an update on the production progress of their order, the sales officer needs to go and ask the production manager.

\subsubsection{Organizational structure}

Organic internal organization When issues or questions regarding certain products or specific work orders appear, office workers are having difficulties in finding direct knowledgeable support. The received support from other office workers tends to have a moral character, due to the varying work tasks 
among them. Most decisions are made by the office workers themselves. However, if it is an especially important or big decision to be made, it is escalated to the CEO. The judgment of whether to escalate or not is based on personal judgment/ experience.

Dynamic collaboration within the value network Product changes and development work is often initiated as a result of shifting customer demands/wishes. However, sometimes such demands may come when their order is already in production.

\subsubsection{Culture}

Willingness to change There exists a focus on solving errors, but these are not used as a learning experience for future betterment. However, decisions concerning sales and production are based on a spreadsheet and calendar system but are manually computed. For office workers, new skills have been learned by inviting instructors. For operators, standardized manuals have been developed for work tasks that have a more routinely character. However, much learning is done by trialand-error. The office workers have different perceptions on how changes on the shop-floor are implemented. Some feel that most changes are initiated by office workers and that there is a lack of contribution from operators, while others feel that when changes are initiated, both office workers and operators work together equally to realize the new ideas.

Social collaboration New ideas are shared with colleagues but are not structured, as it rather happens spontaneously depending on the work situation. There is a mix of much information being documented in IT systems, but also a lot of work tasks that rely on tacit knowledge of the office workers. There is trust in the IT systems, especially in the ERP system that is used to create work orders, but much information is manually inputted.

\subsection{Office workers at company B}

The office workers at company B have different work tasks, including sales and management. Although having other work responsibilities than shop-floor operators, the office workers have direct, or indirect, information and knowledge sharing with the operators that work at other locations in Sweden, e.g., preparation of work orders. All five employees were interviewed concerning their information and knowledge sharing with the operators.

\subsubsection{Resources}

Digital capability Work is heavily dependent on IT systems, e.g., ERP system, service system, spreadsheets, sales planning, and budget offers. Processed data and statistics for planning are manually put into their ERP system, where much computations are done manually.

Structured communication Office workers' communication with operators is carried out in various ways, most usually through their IT systems, but when documented information is unclear, phone calls are made for clarification since their operators are elsewhere stationed.

\subsubsection{Information systems}

Self-learning information processing Most data and information regarding the work orders are stored in the ERP system and are often easily found. While work orders, deliveries, and other information of a follow-up character are relevant and useful for budgeting, information concerning planning is often based on gut-feelings and thus lack applicability and this uncertainty diminishes the usefulness of the documented information.

Information system integration Information from suppliers is processed by the purchaser and information deemed relevant is passed on through to all of the office workers during a planning meeting.

\subsubsection{Organizational structure}

Organic internal organization The office workers' view on the possibility to get support in their work varies. Since the work tasks differ, it is difficult to get directly relevant information, but most felt that it was still possible to get useful feedback from the CEO or other colleagues.

Dynamic collaboration within the value network Information to customers is exchanged by several office workers depending on responsibility areas, e.g., sales consultation, offers, order confirmation, invoicing. Most of this communication is by email or phone.

\subsubsection{Culture}

Willingness to change There exists a focus on solving errors, documentation as lessons learned are encouraged but not executed systematically. Training and continuous education are done in-house to develop routines.

Social collaboration An annual meeting with all employees, including those located elsewhere in Sweden, is arranged, where new ideas are generated for improving the operations. Most work is based on experience. Communication with other office workers is mostly status updates on how work is 
progressing for individuals, giving the opportunity to get feedback.

\subsection{Summary of current Industry 4.0 capabilities and maturity}

The results across the three interview groups are assessed with regards to the capabilities in the four structural areas.

Resources There is a lack of digital capability among operators at company A. Data is collected manually and information sharing does not rely on any digital technology. However, for office workers at company A, digital technology is used to share information and knowledge, but when it is disseminated to the operators, information is printed on paper. Even though digital technology is used, much information and knowledge are shared face-to-face due to them being a small group of people in close proximity to each other. The situation is different for company $\mathrm{B}$, where its operators work at other locations. The office workers at company B are using more digital technology, and the various IT systems are connected to each other in a larger extent.

Information systems Aggregation of data and information processing is made manually without any digital technology support for the operators. Their information exchange with suppliers and customers is almost non-existent. For the office workers at company A, information is processed with the use of their ERP system. Their exchange of information from the operators with suppliers and customers are computerized, but there is a lack of connectivity of their IT systems. This situation is similar to company $\mathrm{B}$, where their connectivity ends within the company and the external information and knowledge sharing are based on computerized information carriers.

Organizational structure Since company A is quite small, they do not use digital technology to support their internal organization. Nor does company A have any connected digital technology for sharing information with customers, which may result in late customization requests. Similarly, for company $\mathrm{B}$, collaboration with customers concerns product customization and is also applying computerization rather than connectivity.

Culture While changes and collaborations occur on the shopfloor for the operators at company $\mathrm{A}$, it is done more hands-on without computerization support. For the office workers, however, their work with changing the shop-floor is often based on data and information from the ERP system. On the contrary for company $\mathrm{B}$, their major change efforts are based on faceto-face experiences rather than computerization.

The current Industry 4.0 capabilities are summarized in Table 4, along with an assessment of the maturity, i.e., stages.
The information and knowledge sharing among shop-floor operators at company $\mathrm{A}$ are in a pre-digitalization era of stage 0 . Their office workers use computerization at stage 1 , both for their own work and for their shop-floor services. Company $\mathrm{B}$, which has their office workers and operators scattered, relies more on computerization at stage 1 . However, for their resources, connectivity at stage 2 is used, while they are investing their internal culture on a pre-digitalization stage 0 face-to-face contact as a counter-balance to the impersonal everyday relationship.

\section{Future Industry 4.0 capabilities}

The discussion on future Industry 4.0 capabilities is based on the current Industry 4.0 capabilities [20] (Sect. 4.4) with regards to the characteristics of Assembly System 4.0 [10] (Sect. 2.2).

Aided assembly Using Industry 4.0 enabling technologies to support the work of operators, e.g., head-worn displays [10], puts demands on a company to develop their capabilities on resources and information systems. It may increase the digital capabilities, but requires a structured communication (resources). Similarly, back-end information systems need to be in place, i.e., in order for contextualized information to be delivered, the shared content needs to be integrated both vertically and horizontally (information systems) [20]. This level of visibility (stage 3) is today lacking at the studied companies.

Intelligent storage management Self-monitored inventory levels that can ensure economic savings [10] may also simplify work for operators and office workers that today manually checks inventory levels, which is the case to today for both studied companies. This kind of self-learning information processing (information systems) with a level of predictive capacity (stage 4) does not exist today at the studied companies.

Self-configured workstation layout Autonomously adjusting the work environment to a specific operator's preferences would optimize assembly activities, but require embedded sensors and actuators [10], which is possible to actualize in real time [9]. However, data governance and IT security (information systems) need to be resolved for processing, storing and managing data and information [20] of individual operators. This level of transparency (stage 4) does not exist today at the studied companies.

Product and process traceability Assessing product quality in real time requires extensive data collection [10] with an automated analysis with the information presented in a manner that supports decision-making (information systems) [20]. Such 


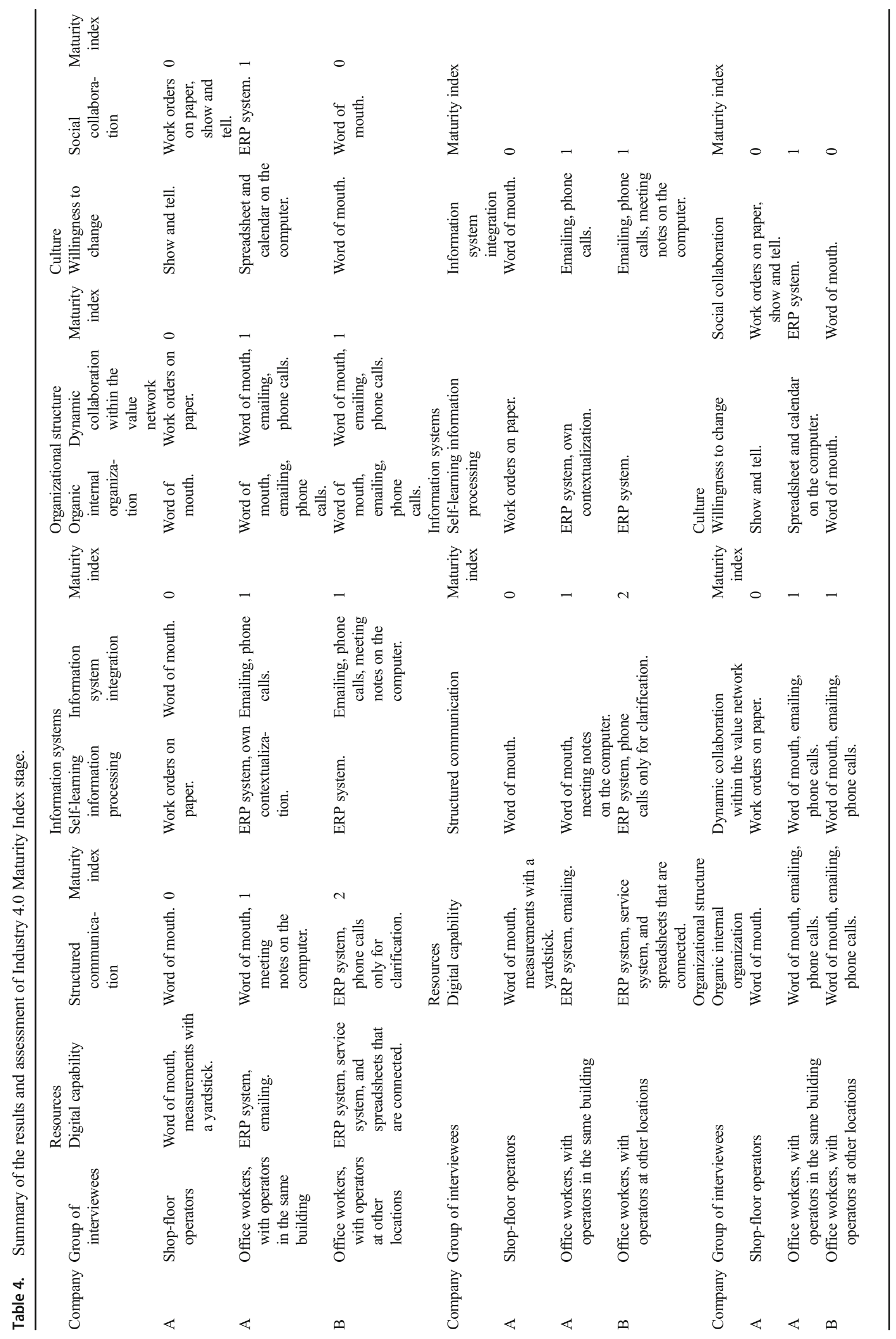


transparency (stage 4) of interaction is not present at the studied companies today.

Late customization In a more agile company, which Industry 4.0 strives for [20], customers will be able to monitor the assembly process and make modifications in production, e.g., additive manufacturing enabled product flexibility [10]. Such capabilities (resources) also put demands on conditions for more dynamic collaboration with the customers (organizational structure). Company A has experience of late customization, but the lack of a predictive capacity (stage 5) something difficult.

Assembly control system To support operators and office workers, both Schuh et al. [20] and Bortolini et al. [10] agree that captured data needs to be processed to meaningful information (information systems). Even though this is done at the studied companies, it is done quite manually and does not reach is not shared through cloud computing [10] predictive capacity (stage 5).

\section{Discussion}

Easy pickings for the case companies are various forms of aided assembly. An example given by a shop-floor operator from company $\mathrm{A}$ is that "I often need to ask for the measurements one extra time when it is a special customization order," which lends evidence to an ineffective transfer of information. While writing down the specific measurements with pen and paper may ensure correct information sharing, the information already exists in the company's ERP system and could be made visible and presented to the operator while performing the assembly task at hand.

While the case companies deal with late customizations, it challenges the internal organization to collaborate with external customers. As a shop-floor operator expresses it: "Sometimes I am given too little information about what to do when there are changes to a product that I am already working on." When the internal organization aims to be organic and agile without a structured communication, nor a production process that supports it, the horizontal integration to customers becomes more important. If the companies' resource capabilities enable late customizations, there are possibilities for a competitive advantage since the customers already start to have such expectations.

The characteristics proposed by Bortolini et al. [10] suggest a developmental direction for companies. Most of the characteristics relate to the structural area of information systems, but resources and organizational structure are also affected. The case companies in this paper are at stage 0 (pre-digitalization) for shop-floor operators and at stage 1 (computerization) for office workers. With an Assembly System 4.0, the companies may reach stages 3,4 , or 5 for the different structural areas, but stage 6 (adaptability) may yet be farther off in the future.

This paper has qualitatively assessed the Industry $4.0 \mathrm{ca}-$ pabilities of two case companies based on their employees' understanding of their working conditions. While previous research requires company managers to possess a certain amount of knowledge about Industry 4.0, this paper exhibits the possibility to explore the subject based on individuals' situational awareness. Concerning the trustworthiness of the research [44], interviewing 15 people is a limitation. However, the credibility is supported by member checks, where interviewees were shown the outcomes for validation. While there are differences between the challenges that large manufacturing companies [12,14] and SMEs [15, 16, 18] are facing, the results exhibit that there also exist many similarities, showing a transferability between the contexts of large manufacturing companies and SMEs. The dependability, or reliability, referring to the lack of serendipity, is shown where the two case companies have some similarities, creating comparability in the results, where the differences between the two companies' office workers are explained by the site conditions of their operators. In this, the qualitative thick descriptions of the interview results are consistent with the quantitative maturity assessment, which supports the confirmability of the research.

The technological implementation of Industry 4.0, such as outlined for Assembly System 4.0 [10], also requires consideration of methodological and social competencies [31]. The interview results show that most reflections by the interviewees remain within the same maturity stage. In this paper, the use of a maturity index [20] has supported the clarification of development directions for sharing information and knowledge in ways unimagined by the interviewees. On the other hand, such new directions may bring unintended implications if certain pre-requisites are not fulfilled, e.g., sufficient knowledge base to be shared [29, 35], humans becoming a central part of planning and their skills correctly assessed [30, 31], and some departments or processes fail to become digitalized on par with others and thus creating a digitalization gap between departments or processes [33, 36]. These examples cause risk for implementations of Industry 4.0 enabling technologies to become misused or disused by Operator 4.0, which is of interest for future research.

\section{Conclusion}

Based on the interviews with shop-floor operators and office workers, the studied companies' current production related information and knowledge sharing practices are to date at a pre-Industry 4.0 maturity stage with regards to structural areas (resources, information systems, organizational structure, and 
culture), i.e., Industry 4.0 enabling technologies with a capability of visibility (stage 3 ) is not implemented to support information and knowledge sharing activities. Digitalization (stages 1 and 2) capabilities have been implemented in various extent among the structural areas. However, shop-floor operators are working in a pre-digitalization stage.

For the studied companies, the future development concerning information and knowledge sharing in a humanfocused Industry 4.0 context needs to start with digitalization for operators. In order to reach visibility (stage 3 ) and integrating IT systems, operators need to catch up office workers in terms of availability of IT systems that support their information and knowledge needs. To further advance towards Operator 4.0, the characteristics of Assembly System 4.0 give hints of the possible outlook for a near future, at stages 3 through 5.

The studied companies have started their digitalization journey, but a continuation of Industry 4.0 progress needs to align with their respective conditions and needs. In order to take advantage of Industry 4.0 enabling technologies, resources, organizational structure, and mostly culture needs not to be neglected, since it is easier to solely be focusing on information systems. Future research needs to be twofold concerning sharing information and knowledge in an Industry 4.0 context. It is important to continue to develop capabilities when it comes to resources and information systems but perhaps even more important to create a supportive organizational structure and culture, as these two structural areas build the foundation and create the demand of workplaces like Assembly System 4.0 for Operator 4.0.

Acknowledgements The research has been carried out within the framework of the research projects Global Assembly Instruction Strategies 2 and MEET-UP, both funded by Vinnova, the Swedish Governmental Agency for Innovation Systems. This support is gratefully acknowledged.

\section{Appendix. Interview questions}

The questions used in the semi-structured interviews, sorted by the guiding principles. Translated from the original Swedish.

Digital capability:

- Which considerations and decisions do you make in your work?

- Do you have any support when making these considerations?
- Do you need to measure, weight, or in any other way find out data or information in your work?

- Do you have any support when making these measurements?

- Concerning data and information that you need for your work, do you compute it yourself or are you in any way presented with the data and information?

Structured communication:

- When you work with a product, when you receive it from the preceding workstation, and when you give the product to the subsequent workstation or there any data or information that the next operator needs to know?

- Is this written anywhere or do you talk to each other?

- In situations when you need information, but cannot find the right person, can you find the information written anywhere?

- Is it alone, or mixed with other unnecessary information, or do you only get specific information that you need?

Information processing:

- Can you give examples of situations when you need to find certain information yourself in order to be able to carry out work tasks?

- Can you give examples of situations when you are provided with the information you need directly?

- Is the information that you use always relevant and applicable, or do you need to make interpretations for work to progress?

- How do you receive information related to your work?

- Do you know of any IT system, where production related information is documented?

Integration:

- What information do you receive that originates from a supplier?

- How do you receive that information?

- What information do you send to a supplier? 
- How do you send that information?

Organic internal organization:

- If you are unsure about how to perform a certain work task, do you feel that you can get help or are able to discuss the issue with someone?

- What type of decisions can you make relating to your work?

- What type of decisions have you made related to your work?

- What type of decision relating to your work is made by others?

- Which production goals does the company have?

- How do you feel that it relates to your daily work?

- How do you work with product changes?

Dynamic collaboration within the value network:

- To what extent do you feel that you are working with your customers?

- How much of your work is affected by customers?

- How much of your work is affecting what your customers can order?

- How do you receive information about customers' specific requests?

- Can you see customers' own drawing or pictures?

Willingness to change:

- How do you feel you are managing mistakes made in production?

- How often do you make changes in production to improve the work environment?

- Is there anything concerning your work tasks that are made automatically by an IT system?

- How is the training of new employees done?

- Are there possibilities for you to learn new competencies that do not yet exist within the company?

- What type of change that has been made at the company originates from an initiative by either you or one of your colleagues in production?
- What type of changes are made by a decision from management?

Social collaboration:

- How have you been involved in changes in production?

- Have you influenced decisions?

- Have you implemented changes?

- Do you have examples of when you are sharing information and experiences about the production with your colleagues?

- Which work tasks do you perform based on your own experiences?

- Which work tasks do you perform based on written information?

Open Access This article is distributed under the terms of the Creative Commons Attribution 4.0 International License (http:// creativecommons.org/licenses/by/4.0/), which permits unrestricted use, distribution, and reproduction in any medium, provided you give appropriate credit to the original author(s) and the source, provide a link to the Creative Commons license, and indicate if changes were made.

\section{References}

1. ElMaraghy W, ElMaraghy H, Tomiyama T, Monostori L (2012) Complexity in engineering design and manufacturing. CIRP Ann 61(2):793-814

2. Yao X, Lin Y (2016) Emerging manufacturing paradigm shifts for the incoming industrial revolution. Int J Adv Manuf Technol 85(58):1665-1676

3. Stock T, Seliger G (2016) Opportunities of sustainable manufacturing in industry 4.0. Procedia CIRP 40:536-541

4. Lasi H, Fettke P, Kemper H-G, Feld T, Hoffman M (2014) Industry 4.0. Bus Inf Syst Eng 6(4):239-242

5. Kagermann H, Wahlster W, Helbig J (2013) Recommendations for implementing the strategic initiative INDUSTRIE 4.0. Acatech national Academy of Science and Engineering. https://www. acatech.de/wp-content/uploads/2018/03/Final_report_Industrie 4.0_accessible.pdf

6. Brettel M, Friederichsen N, Keller M, Rosenberg M (2014) How virtualization, decentralization and network building change the manufacturing landscape: an industry 4.0 perspective. Int J Inf Commun Eng 8(1):37-44

7. Stankovic JA (2014) Research directions for the internet of things. IEEE Internet Things J 1(1):1-7

8. Romero D, Stahre J, Wuest T, Noran O, Bernus P, Fast-Berglund Å, Gorecky D (2016) Towards an Operator 4.0 Typology: A HumanCentric Perspective on the Fourth Industrial Revolution Technologies. In: 46th International Conference on Computers \& Industrial Engineering, Tianjin, China 
9. Mattsson S, Fast-Berglund Å, Åkerman M (2017) Assessing operator wellbeing through physiological measurements in real-time towards industrial application. Technologies 5(4):61-74

10. Bortolini M, Ferrari E, Gamberi M, Pilati F, Faccio M (2017) Assembly system design in the industry 4.0 era: a general framework. IFAC-PapersOnLine 50(1):5700-5705

11. Li D, Paulin D, Fast-Berglund Å, Gullander P, Bligård L-O (2018) Supporting Individual Needs for Intra-Organizational Knowledge Sharing Activities in Pre-Industry 4.0 SMEs. In: Proceedings of 15th International Conference on Intellectual Capital, Knowledge Management \& Organizational Learning, Cape Town, South Africa

12. Johansson PEC, Mattsson S, Moestam L, Fast-Berglund Å (2016) Multi-variant truck production - product variety and its impact on production quality in manual assembly. Procedia CIRP 54:245-250

13. Inkinen H (2016) Review of empirical research on knowledge management practices and firm performance. J Knowl Manag 20(2):230-257

14. Johansson PEC, Malmsköld L, Fast-Berglund Å, Moestam L (2018) Enhancing future assembly information systems - putting theory into practice. Procedia Manufacturing 17:491-498

15. Moeuf A, Pellerin R, Lamouri S, Tamayo-Giraldo S, Barbaray R (2018) The industrial management of SMEs in the era of industry 4.0. Int J Prod Res 56(3):1118-1136

16. Stentoft J, Wickstrøm Jensen K, Philipsen K, Haug A (2019) Drivers and Barriers for Industry 4.0 Readiness and Practice: A SME Perspective with Empirical Evidence. In: Proceedings of the 52nd Hawaii International Conference on System Sciences, Hawaii, United States

17. Chengula Z, Rubio Morato MA, Thurner T, Wiedensohler Y, Martin L (2018) State of Industry 4.0 across six French companies: A pilot study. In: 2018 IEEE International Conference on Engineering, Technology and Innovation (ICE/ITMC), Stuttgart, Germany

18. Sommer L (2015) Industrial revolution - industry 4.0: are German manufacturing SMEs the first victims of this revolution? J Ind Eng Manag 8(5):1512-1532

19. Bittighofer D, Dust M, Irslinger A, Liebich M, Martin L (2018) State of Industry 4.0 across German Companies: A pilot study. In: 2018 IEEE International Conference on Engineering, Technology and Innovation (ICE/ITMC), Stuttgart, Germany

20. Schuh G, Anderl R, Gausemeier J, ten Hompel M, Wahlster W (2017) Industrie 4.0 maturity index. Managing the digital transformation of companies. Acatech - national Academy of Science and Engineering. https://www.acatech.de/wp-content/uploads/2018/03/ acatech_STUDIE_Maturity_Index_eng_WEB.pdf

21. Xu LD, Xu EL, Li L (2018) Industry 4.0: state of the art and future trends. Int J Prod Res 56(8):2941-2962

22. Liao Y, Deschamps F, Loures EFR, Ramos LFP (2017) Past, present and future of industry 4.0-a systematic literature review and research agenda proposal. Int J Prod Res 55(12):3609-3629

23. Bortolini M, Faccio M, Gamberi M, Pilati F (2017) Multi-objective assembly line balancing considering component picking and ergonomic risk. Comput Ind Eng 112:348-367

24. Bortolini M, Faccio M, Gamberi M, Pilati F (2018) Motion analysis system (MAS) for production and ergonomics assessment in the manufacturing processes. Comput Ind Eng in press

25. Rauch E, Linder C, Dallasega P (2019) Anthropocentric perspective of production before and within industry 4.0. Comput Ind Eng in press

26. Leamon TB (1980) The organization of industrial ergonomics - a human: machine model. Appl Ergon 11(4):223-226

27. Karltun A, Karltun J, Berglund M, Eklund J (2017) HTO — a complementary ergonomics approach. Appl Ergon 59(Part A):189-190

28. Ferrer BR, Lastra JLM (2017) An architecture for implementing private local automation clouds built by CPS. In: 43rd annual conference of the IEEE industrial electronics society, Beijing, China

29. Dassisti M, Giovannini A, Merla P, Chimienti M, Panetto H (2018) An approach to support industry 4.0 adoption in SMEs using a coremetamodel. Annu Rev Control in press
30. Taylor MP, Boxall P, Chen JJJ, Xu X, Liew A, Adeniji A (2018) Operator 4.0 or maker 1.0? Exploring the implications of Industrie 4.0 for innovation, safety and quality of work in small economies and enterprises. Comput Ind Eng in press

31. Quattrociocchi B, Mercuri F, d'Arcangelo D, Cristini V (2018) Knowledge management to compete in the digital era: Skills evolution of enterprise systems. In: Proceedings of 19th European Conference on Knowledge Management, Padua, Italy

32. Barreto L, Amaral A, Pereira T (2017) Industry 4.0 implications in logistics: an overview. Procedia Manufacturing 13:1245-1252

33. Müller R, Vette M, Hörauf L, Speicher C, Burkhard D (2017) Lean information and communication tool to connect shop and top floor in small and medium-sized enterprises. Procedia Manufacturing 11: 1043-1052

34. Zhong RY, Xu X, Klotz E, Newman ST (2017) Intelligent manufacturing in the context of industry 4.0: a review. Engineering 3(5):616-630

35. Gasparetto W, Egger G, Giusti A, Rauch E, Riedl M, Matt DT (2018) Intelligent workpiece carrier for distributed data collection and control in manufacturing environments. Procedia Manufacturing 24:190-195

36. Neirotti P, Raguseo E, Paolucci E (2018) How SMEs develop ICTbased capabilities in response to their environment: past evidence and implications for the uptake of the new ICT paradigm. J Enterp Inf Manag 31(1):10-37

37. Brozzi R, D'Amico RD, Pasetti Monizza G, Marcher C, Riedl M, Matt D (2018) Design of Self-assessment Tools to measure industry 4.0 readiness. A methodological approach for craftsmanship SMEs. In: product lifecycle management to support industry 4.0. PLM 2018. IFIP advances in information and communication technology (540):566-578

38. Wiesner S, Gaiardelli P, Gritti N, Oberti G (2018) Maturity models for digitalization in manufacturing - applicability for SMEs. In: Advances in production management systems. Smart manufacturing for industry 4.0. APMS 2018. IFIP advances in information and communication technology (536):81-88

39. Schumacher A, Erol S, Sihn W (2016) A maturity model for assessing industry 4.0 readiness and maturity of manufacturing enterprises. Procedia CIRP 52:161-166

40. Jarrahi F, Pezzotta G, Cimini C, Gaiardelli P (2017) Smart service strategies in Industry 4.0. A proposal of a readiness assessment methodology. In: The Spring Servitization Conference, Lucerne, Switzerland

41. Lichtblau K, Stich V, Bertenrath R, Blum M, Bleider M, Millack A, Schmitt K, Schmitz E, Schröter M (2015) Industrie 4.0 Readiness. IMPULS-Stiftung for mechanical engineering, plant engineering, and information technology. http://www.impuls-stiftung.de/ documents/3581372/4875835/Industrie+4.0+Readniness+ IMPULS+Studie+Oktober+2015.pdf/447a6187-9759-4f25-b186b0f5eac69974

42. Leyh C, Bley K, Schäffer T, Forstenhäusler S (2016) SIMMI 4.0 A Maturity Model for Classifying the Enterprise-wide IT and Software Landscape Focusing on Industry 4.0. In: Federated Conference on Computer Science and Information Systems (FedCSIS), Gdansk, Poland

43. Braun V, Clark V (2006) Using thematic analysis in psychology. Qual Res Psychol 3(2):77-101

44. Lincoln YS, Guba EG (1985) Naturalistic inquiry. In: Naturalistic inquiry. SAGE Publications, Newbury Park

Publisher's note Springer Nature remains neutral with regard to jurisdictional claims in published maps and institutional affiliations. 